\title{
CITY MARKETING: DIMENSÕES IMPORTANTES PARA UMA CIDADE DE BEM VIVER
}

\author{
S.B.N.Ceretta ${ }^{1 *}$; L.M.S.Froemming ${ }^{2}$ \\ 1 Instituto de Educação, Ciência e Tecnologia Farroupilha, 97110-767, Santa Maria, Rio Grande do Sul, Brasil. \\ 2 Universidade Regional do Noroeste do Estado do Rio Grande do Sul, 98700000, Ijuí, Rio Grande do Sul, Brasil. \\ * simone.ceretta@iffarroupilha.edu.br
}

\section{RESUMO}

Este artigo tem o propósito de apresentar o resultado de pesquisa de caráter exploratório, focada em identificar fatores que as pessoas priorizam ao escolher uma cidade de bem viver. As cidades estão inscritas nos primórdios do florescimento da civilização, com os primeiros assentamentos urbanos. Ser citadino portar um status embora urbano adquire significados variados ligados ao imaginário de seus habitantes. A cidade é um espaço criado pelo homem para lhe proporcionar um conjunto de benefícios em diversos sentidos: econômico, social e sentimentos do viver urbano. Assim, rege o movimento das cidades do bem viver. Nesse contexto que se conduz esta pesquisa, utilizando como meio a coleta de dados no método survey. Os resultados identificam atributos valorizados por segmentos da sociedade identificados em formas diferenciadas de papeis, quais sejam: moradores, estudantes, trabalhadores, investidores e visitantes. Os papéis às vezes na dimensão unitária em outros de modo polivalente apontam interessantes ambições do cidadão ao definir suas prioridades.

\section{CITY MARKETING: KEY DIMENSIONS OF A GOOD LIVING CITY}

\begin{abstract}
This article aims to present the results of exploratory research focused on identifying factors that people prioritize when choosing a city of good living. Cities are given in the beginning of the flowering of civilization, with the first urban settlements. Being city carry a status although urban acquires different meanings attached to the imagination of its inhabitants. The city is a space created by man that gives you a number of benefits in many ways: economic, social and feelings of urban
\end{abstract}

living. Thus, governs the movement of cities of the good life. In this context that leads this research, using as a means of data collection in the survey method. The results identify attributes valued by segments of society identified in different forms of roles, namely: residents, students, workers, investors and visitors. The papers sometimes the unitary dimension in other multipurpose point so interesting ambitions of citizens to define their priorities.

KEYWORDS: Good living; attributes; Cities. 


\section{INTRODUÇÃO}

A globalização, afirma Honoré (2003) é a soma de avanços tecnológicos e também geopolíticos trazendo oportunidades e também ansiedades e remete à questão: "estamos preparados para as mudanças?" Remetendo ao contexto das comunidades vale lembrar a provocação de Kanter (1966) "como as cidades e regiões podem atrair e manter melhores empresas e melhores empregos? Como podem viabilizar as forças globais para obter vantagens locais?" (p. XVII). A autora segue a provocação indagando como ser mestres e não vítimas da mudança, provocação que requer a abordagem proativa no encaminhamento das políticas de definição de "em que tipo de cidade queremos viver?"

O Marketing de lugares ou city marketing consiste em utilizar ferramentas do marketing para enfrentar o desafio do crescimento no âmbito de lugares atraindo investimentos, moradores e visitantes, demonstrando como as comunidades e as regiões podem competir na economia global e desenvolver-se.

Assim como administrar uma organização torna-se um desafio complexo, gerir cidades mostra-se ainda mais abrangente e desafiador devido às muitas varáveis e fatores internos e externos envolvidos que impactam diretamente na tomada de decisão acerca de que ações executar. Nesse contexto, o objetivo desse estudo é investigar o que torna um lugar(cidade) atrativo(a) ao público quando se exerce papel de morador, estudante, trabalhador investidor e/ou visitante.

Torna-se fundamental, a construção de um planejamento estratégico requerendo informações para embasar a projeção no futuro. Assim desponta a relevância de uma pesquisa com os cidadãos a fim de identificar os atributos considerados prioritários para que uma cidade seja atrativa aos diversos papéis que ele exerce. Diante dos resultados é possível uma tomada de decisão mais eficaz na construção de uma cidade considerada ideal para o bem viver.

\section{REVISÃO BIBLIOGRÁFICA}

O Marketing ao longo das décadas vem conquistando cada vez mais espaço dentro do ambiente organizacional. Entretanto, nos últimos anos surgem novas abordagens nesta área e sua abrangência passa a atingir também as cidades, ou localidades, refletindo direta e/ou indiretamente no processo de desenvolvimento da sociedade como um todo.

Kotler e Armstrong (1999, p. 3) definem marketing como o "processo social e gerencial através do qual indivíduos e grupos obtém aquilo que desejam e de que necessitam, criando e trocando produtos e valores uns com os outros." Essa dimensão social mostra o papel desempenhado pelo marketing na sociedade, no sentido de proporcionar um padrão de vida superior (COBRA, 2009). Quando se menciona a questão dos benefícios à sociedade, melhorias em sua qualidade de vida emerge a ideia do marketing de lugares, afinal qualquer região necessita melhorar a comercialização de seus produtos locais, promover os valores e a imagem formando uma gama de vantagens de diferenciação, e, essencialmente manter sua população atuante e satisfeita com o modus vivendi.

O Marketing de lugares, para Kotler et al (2006) consiste em utilizar ferramentas do marketing para enfrentar o desafio do crescimento no âmbito de lugares atraindo investimentos, moradores e visitantes, demonstrando como as comunidades e as regiões podem competir e desenvolver-se na economia global

Assim, os administradores devem estabelecer uma estratégia clara que possa direcionar os seus esforços no sentido de criar uma oferta de valor que seja relevante para seus públicos-alvo. A definição dos públicos-alvo é crucial para o sucesso do planejamento. 
Essa dimensão do marketing tem sido discutida por vários autores (KEARNS; PHILO, 1993; CIDRAIS, 1998; KOTLER et al 2006; VAN DEN BER; BRAUN, 2002) e recebe diversas denominações como: place marketing, city marketing, marketing territorial, marketing urbano, marketing de lugares e marketing de cidades. As abordagens envolvem duas perspectivas: uma, considerada parte de uma nova economia política para as cidades e regiões, e outra, assume estratégias mais práticas que transportam o marketing tipicamente empresarial para a cidade. Entretanto, é possível agregar as duas visões, presente na recente transformação na governança urbana e no envolvimento da esfera empresarial e de mercado nos processos de desenvolvimento local, através da promoção do lugar.

O marketing de lugares emerge então, como um dos elementos fulcrais do planejamento estratégico das cidades e regiões, partindo de suas singularidades e especificidades, integrando-as e projetando-as em um contexto de competitividade global, visando identificar sua vocação e visão, promovendo-as e afirmando-as.

Kotler et al (2006) defendem que o objetivo do marketing de lugares é desenhar uma comunidade que satisfaça as necessidades dos diversos grupos de utilizadores (visitantes, residentes e trabalhadores), as empresas e os mercados desse mesmo local. Antunes (2002) aponta a validade do conceito não somente às grandes cidades, mas também para as pequenas localidades que podem reforçar a sua competitividade e a economia local, através da identificação e exploração de suas vantagens distintivas. São estas vantagens que resultam da soma dos fatores que a tornam única em um contexto de competitividade.

O marketing voltado às cidades tem como intuito a promoção da prosperidade da comunidade urbana, utilizando-se da inovação, do conhecimento e da formação para direcionar estratégias de valorização e promoção de uma cidade (VAN DEN BERG; BRAUN, 1999). Assim, estratégias podem ser direcionadas a diferenciar cidades atraindo investimentos, empresas e conhecimento passando a cidade a se tornar mais competitiva.

Vale citar Santos (2003) ao referir que a cidade é um polo indispensável ao comando técnico da produção. Além do mais é um lugar de residência de trabalhadores, local das instituições, da administração publica, das empresas, formando uma mescla de formas de vida, de atividades, de valores, em constantes reorganizações. (2006):

O marketing de lugares abrange quatro principais atividades, na abordagem de Kotler et al

- O desenvolvimento de um posicionamento e uma imagem fortes e atraentes;

- O estabelecimento de incentivos atraentes para os atuais e os possíveis compradores e usuários de seus bens e serviços;

- O fornecimento de produtos e serviços locais de maneira eficiente;

- A promoção de valores e a imagem do local de uma maneira que os possíveis usuários conscientizem-se realmente de suas vantagens diferenciadas.

As comunidades, comumente se concentram apenas em uma ou outra atividade mercadológica, geralmente as promocionais. Portanto, apesar da tendência tradicional do marketing estar voltada para o produto, ele tem sido utilizado como ferramenta de promoção econômica de cidades, na realização de grandes eventos, em reestruturações urbanas profundas e para a promoção turística dos territórios, das empresas e das pessoas. Cabe a tarefa de divulgar e promover o amplo espectro que a adequada utilização do conceito de marketing propicia.

São considerados como públicos-alvo no marketing de lugares: visitantes; moradores e trabalhadores; investidores comerciais e industriais e mercados de exportação. Para atrair estes 
públicos Kotler et al (2006) propõe quatro amplas estratégias que são: marketing de imagem, marketing de atrações, marketing de infraestrutura e marketing de pessoas.

Marketing de imagem: sem uma imagem original e diferenciada, um lugar potencialmente atraente pode passar despercebido em meio ao vasto mercado de lugares disponíveis. Dessa forma, uma das metas do marketing de imagem é criar um slogan criativo que contenha uma ideia de fundamento.

Marketing de atrações: existem lugares com atrações naturais, outros com notável patrimônio histórico, lugares que abrigam edifícios famosos mundialmente, lugares que desfrutam o benefício de ter ginásios esportivos valorosos, lugares com centro de convenções e exposições gigantescos, ou, com calçadões.

Marketing de infraestrutura: nem a imagem, nem as atrações conseguem oferecer a resposta completa para o desenvolvimento de um lugar, sendo necessária uma infraestrutura eficaz na base. São apontados como melhorias neste quesito: ruas e rodovias, aeroportos e redes de telecomunicações, portos e investimentos em tecnologia de comunicação.

Marketing de pessoas: pode ser feito através de cinco grupos de pessoas - famosas, líderes entusiasmados (empresariais e políticos habilidosos), pessoas competentes, pessoas com perfil empreendedor e pessoas que se mudaram para o lugar.

Como participantes do marketing de lugares, Kotler et al (2006) mencionam: participantes do setor público, do setor privado, participantes regionais, nacionais e internacionais. Conceito muito próximo da proposição da tríplice hélice desenvolvida por Etzkowitz (2002), que envolve nas políticas de desenvolvimento, o papel do Governo, Empresas, Universidades e na denominada $4^{\mathrm{a}}$ hélice prevê a incorporação da sociedade civil organizada.

O marketing de local é bem sucedido quando os contribuintes, cidadãos, trabalhadores e empresas obtém satisfação por pertencerem à comunidades e também, quando seus visitantes, novos negócios e investidores atingem suas expectativas (KOTLER; HAIDEN; REIN, 1993, p. 16).

Porter (1995) indica que o setor privado, o governo e as organizações comunitárias terão papéis cruciais a desempenhares na revitalização da economia das cidades.

Apesar da tendência tradicional do marketing estar voltada para o produto, ele tem sido utilizado como ferramenta de promoção econômica de cidades, na realização de grandes eventos, em reestruturações urbanas profundas e para a promoção turística dos territórios, das empresas e das pessoas.

Cidades do Bem viver é um novo conceito oriundo do movimento calcado no Slow Food que apregoa um modo de viver com mais tranquilidade e qualidade de vida. O movimento batizado de Citta Slow ou Cidades do Bem Viver, relata Honoré (2014) nasceu na cidade de Bra na Itália e em 1999 passou a ser modelo de uma nova proposta de cidade que preza as regras de um novo modo de viver privilegiando o bem estar de seus cidadãos.

O movimento consta com um manifesto que enumera cinquenta e cinco compromissos, citase entre eles: 1) diminuir o barulho e o tráfego; 2) aumentar espaços verdes e zonas de pedestres; 3 ) apoiar os agricultores da região, bem como as lojas, os mercados e os restaurantes que vendem seus produtos; 4) promover tecnologias de proteção ao meio ambiente; 5) preservar as tradições estéticas e culinárias locais; 6) estimular espírito de hospitalidade e solidariedade local (p. 105).

Outro movimento que se alastra é o denominado de Cidades em Transição (Transition Tows) criado pelo inglês Rob Hopkins que tem o objetivo de transformar as cidades em modelos sustentáveis, e se propõe o fortalecimento da comunidade e o redesenho de espaços, ações, 
interações e relações, engajando pessoas, comunidades e instituições para juntas pensarem e implementarem ações necessárias - de curto, médio e longo prazo - para fazer frente a desafios que se manifestam (VIVACQUA, 2012).

O movimento está presente em 31 países no mundo e no Brasil. O movimento vem sendo implantado em bairros ou regiões, de maneira experimental, devido a sua grande extensão territorial.

\section{MATERIAIS E MÉTODOS}

Trata-se de um estudo exploratório e descritivo, que utilizou como coleta de dados, o método survey que se utiliza de um questionário estruturado apliาcado a uma amostra de uma população e que se destina a obter informações específicas dos entrevistados (MALHOTRA, 2001).

Os questionários, veículo da coleta de dados, constituíram-se de questões de múltipla escolha nas quais os entrevistados eram instados a responder, assumindo um ou mais papéis, visualizando-se como morador, estudante, trabalhador, investidor, visitante. Dos respondentes $24,21 \%$ assumiram todos os papéis, $31,58 \%$ apenas um, $20 \%$ apenas dois, $18,95 \%$ três papéis, $5,26 \%$ quatro e, $24,21 \%$ assinalaram as cinco alternativas. A amostra está constituída de 95 respondentes

Os resultados são apresentados por meio de gráficos de distribuição de frequência no formato de quadros e tabelas. Caracteriza-se, portanto, como um estudo de caráter quantitativoqualitativo, mesclando a abordagem teórica construída com as informações coletadas com os sujeitos do estudo.

\section{RESULTADOS E DISCUSSÃO}

A essência do marketing encontra-se na satisfação do consumidor o que se torna possível quando se conhece as reais necessidades e desejos do público a que se propõe atingir. No caso específico do marketing de cidades, o público-alvo - os cidadãos - apresentam necessidades distintas compatíveis com o papel(is) que estão exercendo na sociedade.

Pensar na construção de uma cidade atrativa requer em um primeiro momento descobrir o que esse cidadão considera prioritário para que se sinta atraído a residir em tal município, por isso a relevância de um planejamento calcado em informações que irão orientar as decisões da gestão pública.

Para lidar com as cidades e seus problemas é preciso entender as cidades. É nelas que as soluções são desenhadas e levadas à prática. É nas cidades que a sustentabilidade global acontece e começa a tomar forma, apregoa West (2014). Desta forma se justifica a pesquisa, cujos resultados se apresentam; pois é com os públicos que se identificam suas veleidades sobre uma cidade do bemviver.

O estudo realizado traz nesse sentido dados seminais pertinentes ao se pensar o planejamento estratégico de uma cidade. Conhecer o público e suas idiossincrasias é essencial identificando-se suas peculiaridades e preferências em relação a cidades. O perfil dos entrevistados, em um total de 95 respondentes mostrou-se variado, com predominância de algumas características. Em relação a ocupação dos respondentes houve concentração em 12\% de auxiliares administrativos, $10 \%$ de professores. Agricultores e estagiários 8,5\% cada, seguidos de estudantes e vendedores $7,4 \%$ cada estrato. Os demais se diluem em 21 diversificadas ocupações. 
No gráfico 1 é possível identificar que 64,21\% são moradores perenes do local, nasceram e sempre residiram na mesma cidade, outros $20 \%$ residem há mais de 10 anos, ou seja, mais de $84 \%$ possui uma relação antiga com sua cidade.

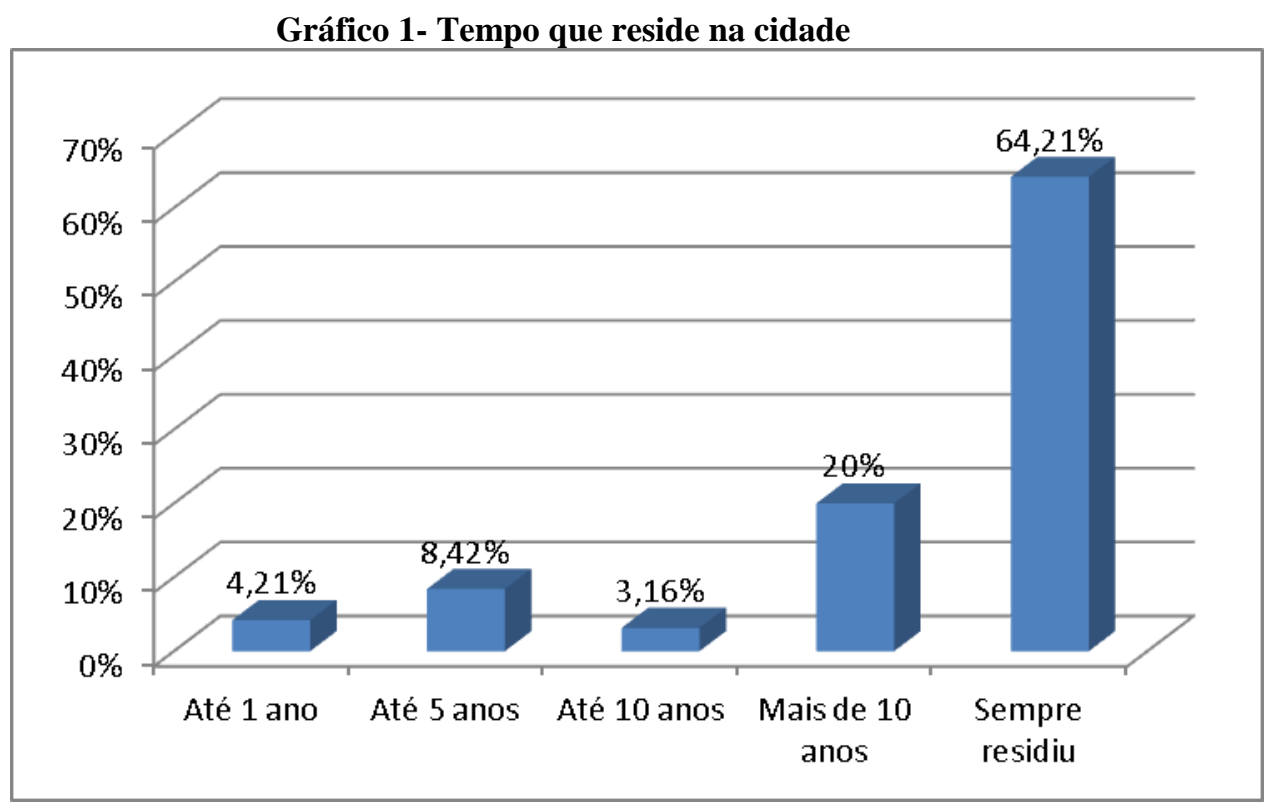

Fonte: pesquisa de campo.

A amostra caracteriza-se como jovem: $61 \%$ possuem entre 18 e 28 anos e $80 \%$ situam-se na faixa de 18 a 40 anos, gráfico 2, com predominância (60\%) do sexo feminino. Com relação, a renda mensal, gráfico 3 , se demonstra que mais de $70 \%$ detém de 2 a 5 salários mínimos.

\section{Gráfico 2- Faixa etária dos respondentes}

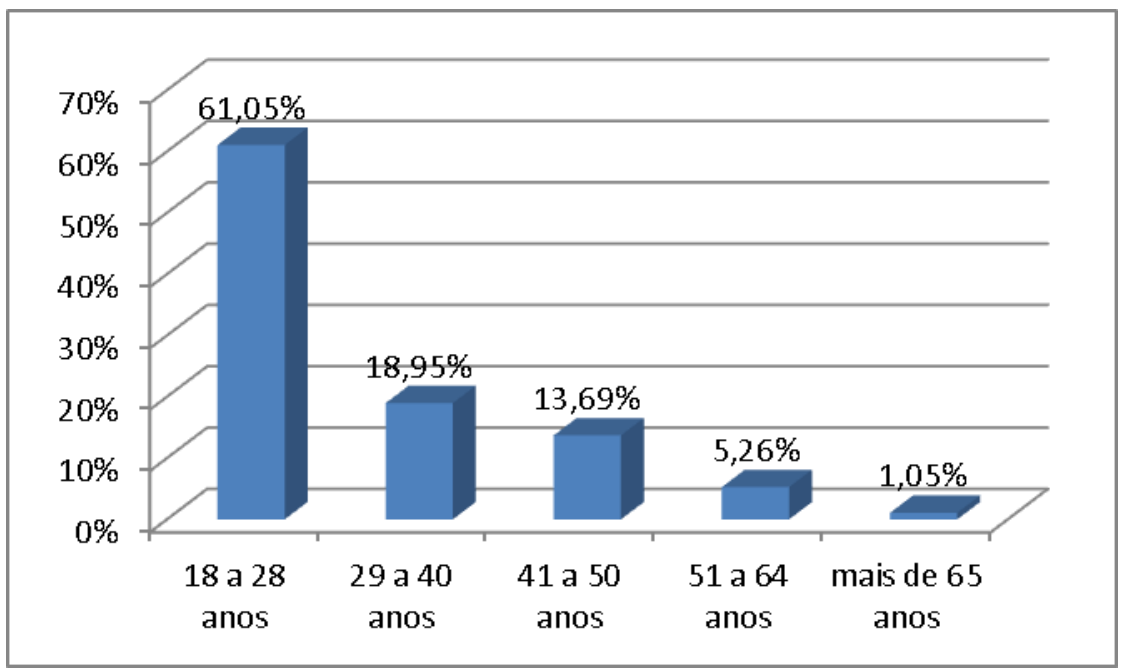

Fonte: pesquisa de campo 


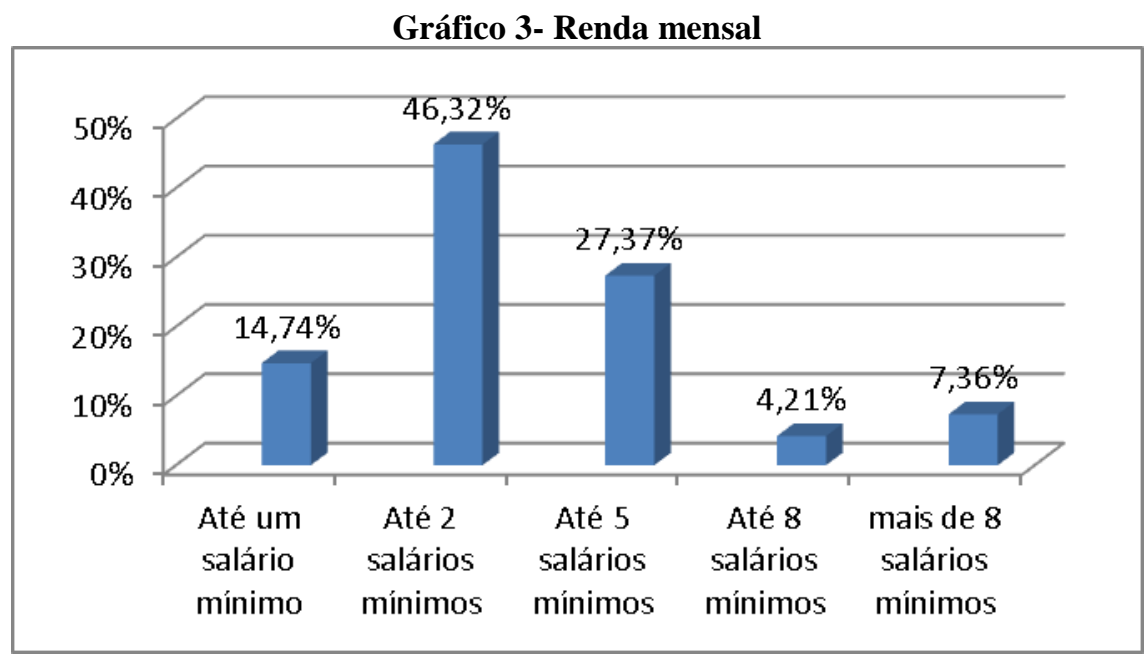

Fonte: pesquisa de campo.

Em relação ao nível de escolaridade a amostra apresenta alta escolaridade 48,42\% possuem ou estão cursando ensino superior, enquanto que $29,47 \%$ têm ensino médio completo (Gráfico 04).

Gráfico 4- Nível de Escolaridade

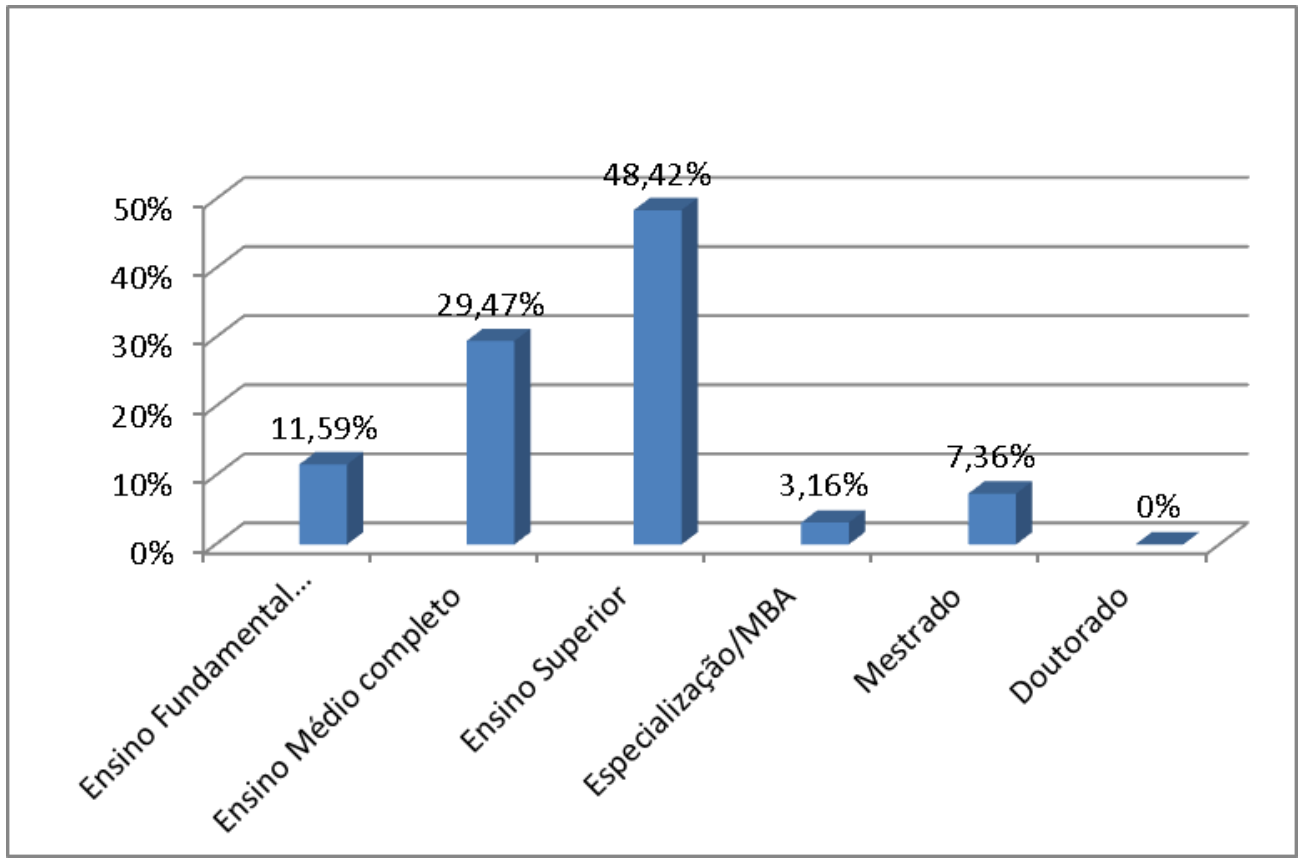

Fonte: pesquisa de campo

As origens dos respondentes são de municípios diversos da região Noroeste do Estado do Rio Grande do Sul, prevalecendo residentes em 04 cidades: Panambi (17,9\%), Santa Rosa (15\%), Santo Augusto (10\%) e Ijuí (8\%).

Os resultados da investigação apontam que os atributos considerados prioritários variam de acordo com o papel que cada respondente exerce na sociedade. Os atributos foram divididos em atributos núcleo e atributos secundários, considerando a opinião dos respondentes enquanto: moradores, estudantes, trabalhadores, investidores e visitantes. 
Os atributos núcleo são aqueles considerados determinantes na opinião do cidadão para uma cidade ser considerada ideal. Já os secundários incluem características cujo significado não é menos importante ou marginal, apenas refere-se a uma dimensão de menor impacto. $\mathrm{O}$ modelo proposto por Walker para avaliar a qualidade enfatiza a característica de produtos apresentarem o componente central núcleo e a agregação de componentes secundários que contribuem para a operacionalização do todo (WALKER, 1995), conceito que se utilizou para o estudo das cidades.

No Quadro 1 apresentam-se em ordem de classificação os cinco atributos prioritários apontados na pesquisa. Como os sujeitos da amostra poderiam escolher o(s) papel(is) que assumiriam, o número de respondentes varia conforme cada um dos papéis assumidos, identificados nos parênteses.

Quadro 1- Atributos núcleo/prioritários

\begin{tabular}{|c|c|c|c|c|c|c|c|c|c|c|c|c|c|c|}
\hline \multicolumn{3}{|c|}{ Moradores (85) } & \multicolumn{3}{|c|}{ Estudantes (58) } & \multicolumn{3}{|c|}{ Trabalhadores (62) } & \multicolumn{3}{|c|}{ Investidores (27) } & \multicolumn{3}{|c|}{ Visitantes (30) } \\
\hline$\overline{1^{1^{\circ}}}$ & $\begin{array}{l}\text { Hospitais } \\
\text { e Postos } \\
\text { de Saúde }\end{array}$ & $15,78 \%$ & $\overline{\mathbf{1}^{\circ}}$ & $\begin{array}{l}\text { Escolas e } \\
\text { Universidades } \\
\text { de qualidade }\end{array}$ & $\begin{array}{l}15,86 \\
\%\end{array}$ & $\overline{\mathbf{1}^{\mathbf{0}}}$ & $\begin{array}{l}\text { Oferta de } \\
\text { Empregos }\end{array}$ & $12,89 \%$ & 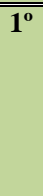 & $\begin{array}{l}\text { Serviços de } \\
\text { comunicação } \\
\text { eficientes }\end{array}$ & $11,86 \%$ &  & 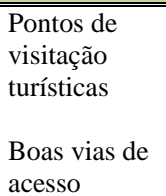 & $9,33 \%$ \\
\hline$\overline{2^{\circ}}$ & $\begin{array}{c}\text { Energia, } \\
\text { água } \\
\text { esgoto }\end{array}$ & $12,71 \%$ & $\overline{2^{\circ}}$ & $\begin{array}{l}\text { Transporte } \\
\text { público } \\
\text { eficiente }\end{array}$ & $9,31 \%$ & $2^{\circ}$ & $\begin{array}{l}\text { Comércio/ } \\
\text { Indústria } \\
\text { desenvolvid } \\
\text { os }\end{array}$ & $10,63 \%$ & $22^{\circ}$ & $\begin{array}{l}\text { Comércio/Ind } \\
\text { ústria } \\
\text { desenvolvidos } \\
\text { Boas vias de } \\
\text { acesso }\end{array}$ & $9,63 \%$ & $2^{\circ}$ & $\begin{array}{l}\text { Restaurantes } \\
\text { Rede de } \\
\text { Hotelaria }\end{array}$ & $7,33 \%$ \\
\hline $\mathbf{3}^{\circ}$ & $\begin{array}{l}\text { Segurança } \\
\text { Pública }\end{array}$ & $9,65 \%$ & $\overline{3^{\circ}}$ & $\begin{array}{l}\text { Bibliotecas } \\
\text { Públicas }\end{array}$ & $8,28 \%$ & $3^{\circ}$ & $\begin{array}{l}\text { Segurança } \\
\text { Pública }\end{array}$ & $7,74 \%$ & $\mathbf{3}^{\circ}$ & $\begin{array}{l}\text { Energia, água, } \\
\text { esgoto }\end{array}$ & $8,15 \%$ & $3^{\circ}$ & $\begin{array}{l}\text { Praças, ruas, } \\
\text { arborização }\end{array}$ & $6,67 \%$ \\
\hline$\overline{4^{\circ}}$ & $\begin{array}{c}\text { Coleta } \\
\text { Seletiva } \\
\text { de Lixo } \\
\text { Boas Vias } \\
\text { de acesso }\end{array}$ & $7,29 \%$ & $\overline{4^{\circ}}$ & $\begin{array}{l}\text { Livrarias } \\
\text { Serviços de } \\
\text { Comunicação } \\
\text { eficientes }\end{array}$ & $6,90 \%$ & $4^{\circ}$ & $\begin{array}{l}\text { Boas vias } \\
\text { de acesso }\end{array}$ & $7,10 \%$ & $\mathbf{4}^{\circ}$ & $\begin{array}{l}\text { Mão-de-obra } \\
\text { qualificada }\end{array}$ & $7,42 \%$ & $\mathbf{4}^{\circ}$ & $\begin{array}{l}\text { Riquezas } \\
\text { Naturais } \\
\text { Lazer e } \\
\text { entreteniment } \\
\text { o } \\
\text { Centro de } \\
\text { informações } \\
\text { turísticas } \\
\text { Segurança } \\
\text { Pública }\end{array}$ & $5,33 \%$ \\
\hline$\overline{5}^{\circ}$ & $\begin{array}{l}\text { Habitação } \\
\text {-Moradia }\end{array}$ & $5,88 \%$ & $\overline{5^{\circ}}$ & $\begin{array}{l}\text { Boas vias de } \\
\text { acesso }\end{array}$ & $\overline{5,52 \%}$ & $\overline{5^{\circ}}$ & $\begin{array}{l}\text { Transporte } \\
\text { público } \\
\text { eficiente }\end{array}$ & $6,77 \%$ & $\overline{5^{\circ}}$ & $\begin{array}{l}\text { Escolas e } \\
\text { Universidades } \\
\text { de qualidade }\end{array}$ & $5,94 \%$ & $\overline{5^{\circ}}$ & $\begin{array}{l}\text { Feiras e } \\
\text { parques de } \\
\text { eventos e } \\
\text { exposições }\end{array}$ & 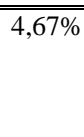 \\
\hline
\end{tabular}

Fonte: pesquisa de campo.

$\mathrm{Na}$ categoria de moradores, dos 85 respondentes, $15,78 \%$ apontam a relevância da existência de hospitais e postos de saúde e $12,71 \%$ destacam como essencial a infraestrutura básica quanto ao fornecimento de energia, água e esgoto. A segurança pública foi mencionada por 9,65\%, seguida pela coleta seletiva de lixo e as boas vias de acesso empatadas em 7,29\%, enquanto que $5,88 \%$ priorizam as condições e opções de habitação e moradia da cidade.

Os resultados deflagram atributos gerados por problemas contemporâneos enfrentados pela sociedade, mencionados por Kotler, Hermawan e Setiawan (2010), como as crises financeiras, climáticas com aumento da poluição e, as lentas taxas de crescimento dos países. Leite (2012) argumenta que a questão das mudanças climáticas é o mais premente problema ambiental, social e econômico que a sociedade enfrenta e, suas consequências são globais e de longa duração. Como algumas consequências têm-se doenças, falta de água e energia, aumento da criminalidade, produção de lixo em demasia com problemas de descarte e problemas de fluxo viário, o que corrobora as preocupações apresentadas na pesquisa. Enquanto moradores, as pessoas precisam 
residir em uma cidade que ofereça soluções para essas necessidades cada vez mais presentes em seu cotidiano de vida e que impacta diretamente sobre a qualidade de vida no local.

No papel de estudantes, dos 58 que assim se posicionaram, 15,86\% consideram essencial a existência de escolas e universidades de qualidade no município, fator esse prioritário e que em muitos casos os fazem optar por outra cidade para estudar e inclusive morar. Nessa avaliação, geralmente valorizam instituições públicas de ensino e que possuam uma boa reputação e credibilidade. Outros $9,31 \%$ mencionaram a importância de transporte público eficiente, uma vez que enquanto estudantes utilizam muito este tipo de serviço para o deslocamento intermunicipal e urbano. A existência de bibliotecas públicas é primordial para 8,28\%, livrarias e serviços de comunicação eficientes (telefone, internet) para $9,60 \%$ e, $5,52 \%$ consideram as boas vias de acesso à cidade, fundamental para uma cidade ser considerada atrativa aos estudantes.

Analisando os 62 respondentes que assumiram o papel de trabalhadores, identificou-se que $12,89 \%$ valorizam a oferta de empregos como atributo principal, caracterizando-se como uma forma de se conquistar uma vaga de trabalho como também, visando progressão de carreira em novo emprego. Para 10,63\% é importante que o comércio e/ou indústria sejam desenvolvidos, o que gera empregos, maior circulação de dinheiro e acréscimo de renda. A Segurança pública foi indicada por $7,74 \%$, seguida de boas vias de acesso à cidade $(7,10 \%)$ e a existência de transporte público eficiente $(6,77 \%)$ utilizado por grande parte dos trabalhadores em seu deslocamento diário.

$\mathrm{Na}$ categoria de investidores, composta por 27 respondentes, $11,86 \%$ priorizaram os serviços de comunicação eficiente como atributo núcleo. O resultado aponta para a nova realidade dos empreendedores, que na atualidade realizam negócios em nível global sendo essencial a disponibilização de meios de comunicação eficazes e ágeis. Independente do tamanho da empresa, aquelas que desejam expandir dependem desses serviços para a geração de negócios. Considere-se ainda que grande contingente de empresas que buscam estabelecer-se em cidades do porte dos componentes da amostra, são representações de redes com sede em outros municípios e a pronta comunicação é essencial a seus propósitos.

O comércio e/ou indústria desenvolvidos foi citado por 9,63\%, uma vez que quando uma localidade é próspera em termos de vendas e produção acaba atraindo novos investidores e compradores tornando-se uma área propícia ao consumo e à consequente lucratividade. Outros $8,15 \%$ mencionam a infraestrutura de água, energia e esgoto, como importante para garantir a operacionalização e o funcionamento dos empreendimentos. Os demais 7,42\% apontam a existência de mão-de-obra qualificada como fundamental, seguida de escolas e universidades de qualidade $(5,94 \%)$. Esses atributos em especial, trazem à tona um novo perfil de gestor preocupado em investir em uma cidade que tenha pessoas qualificadas ou em qualificação, capazes de atuar em suas empresas prestando um serviço de excelência. Existe a preocupação de se ter colaboradores qualificados em número suficiente para atender a demanda da classe empresarial, evitando o transtorno de ter que se recrutar pessoas de outros municípios, o que gera maiores problemas e custos (transporte e alimentação) para uma organização.

Com relação ao papel de visitantes, 30 responderam nessa categoria. Em primeiro lugar, os atributos mais mencionados foram pontos de visitação turística e as boas vias de acesso, cada um com $9,33 \%$ das respostas. São variáveis essenciais uma vez que a estrutura viária torna o acesso do visitante mais fácil para encontrar e se deslocar até os pontos de visitação, que no caso dessa categoria são o que os atraem especificamente as pessoas para um município. Com 7,33\% cada, destacaram-se os restaurantes e a rede de hotelaria, serviços básicos para turistas desfrutarem de uma localidade com comodidade. Atributos como riquezas naturais, lazer e entretenimento, centro de informações turísticas e segurança pública foram apontados por 5,33\% como atrativos, seguidos 
de 4,67\% que mencionaram a importância das feiras e parques de eventos e exposições para os fazerem querer visitar uma cidade.

Identifica-se que todos os atributos mencionados são específicos ao cotidiano e ao interesse do público e o papel que exercem na sociedade. É possível identificar no Quadro 02, que atributos considerados como primários para determinados papéis surgem como secundários em outros e viceversa. Os dados evidenciam que, tais características foram mencionadas nas questões em cada um dos papéis, entretanto, em menor frequência, o que classifica esses atributos como secundários.

Cabe ressaltar que os resultados da pesquisa representam um contexto social, da realidade vivida pelos pesquisados dentro de um cenário sociocultural e econômico. Por exemplo, no papel de visitantes a variável comércio e/ou indústria desenvolvidos, aparece como atributo secundário. Em outras regiões, estados e/ou países esse atributo provavelmente estaria entre os prioritários, uma vez que o visitante utiliza como forma de lazer e entretenimento as compras em comércios locais.

Quadro 02- Atributos secundários

\begin{tabular}{|c|c|c|c|c|}
\hline Moradores & Estudantes & Trabalhadores & Investidores & Visitantes \\
\hline $\begin{array}{l}\text { - Rede de Hotelaria } \\
\text { - Pontos de } \\
\text { visitação turísticas } \\
\text { - Oportunidade de } \\
\text { participação em } \\
\text { fóruns populares } \\
\text { - Espaço de Cultura }\end{array}$ & \begin{tabular}{|l} 
- Centro de \\
Informações \\
Turísticas \\
- Pontos de \\
Visitação \\
turísticas \\
- Limpeza urbana \\
- Restaurantes \\
- Coleta seletiva de \\
lixo
\end{tabular} & \begin{tabular}{|l} 
- Livrarias \\
- Bibliotecas \\
públicas \\
- Feiras e parques \\
de eventos e \\
exposições \\
- Receptividade da \\
população \\
- Rede de Hotelaria
\end{tabular} & $\begin{array}{l}\text { - Habitação- } \\
\text { Moradia } \\
\text { - Espaços de } \\
\text { cultura } \\
\text { - Restaurantes } \\
\text { - Praças, ruas, } \\
\text { arborização } \\
\text { - Transporte } \\
\text { público eficiente }\end{array}$ & $\begin{array}{l}\text { - Serviços de } \\
\text { comunicação } \\
\text { eficientes } \\
\text { - Transporte público } \\
\text { eficiente } \\
\text { - Escolas e } \\
\text { Universidades de } \\
\text { qualidade } \\
\text { - Livrarias } \\
\text { - Comércio/Indústria } \\
\text { desenvolvidos }\end{array}$ \\
\hline
\end{tabular}

Fonte: pesquisa de campo

Outra análise que se pode fazer diante dos resultados expostos, é que alguns quesitos encontram-se presentes entre os cinco prioritários para mais de um papel, o que os torna mais relevantes ainda, para tornar uma cidade atrativa. São eles: as boas vias de acesso à cidade, o transporte público eficiente, a segurança pública, a infraestrutura básica (energia, água, esgoto), as escolas e universidades de qualidade, os serviços de comunicação eficientes e o comércio/indústria desenvolvidos (quadro 3). Ao estabelecer um planejamento estratégico de uma cidade devem-se utilizar tais quesitos nas ações para promover melhorias que venham ao encontro dessas necessidades apresentadas pelos cidadãos.

Quadro 3- Os públicos e as variáveis mais importantes

\begin{tabular}{||l||l||l||l||l||l||l||}
\hline $\begin{array}{c}\text { Transporte } \\
\text { Público } \\
\text { eficiente }\end{array}$ & $\begin{array}{c}\text { Boas vias de } \\
\text { acesso }\end{array}$ & $\begin{array}{c}\text { Energia, } \\
\text { água, esgoto }\end{array}$ & $\begin{array}{c}\text { Segurança } \\
\text { Pública }\end{array}$ & $\begin{array}{c}\text { Escolas e } \\
\text { Universidades } \\
\text { de qualidade }\end{array}$ & $\begin{array}{c}\text { Serviços de } \\
\text { comunicação } \\
\text { eficientes }\end{array}$ & $\begin{array}{c}\text { Comércio/ } \\
\text { Indústria } \\
\text { desenvolvidos }\end{array}$ \\
\hline \hline$\bullet$ Estudantes & $\bullet$ Moradores & $\bullet$ Moradores & $\bullet$ Moradores & $\bullet$ Estudantes & $\bullet$ Estudantes & $\bullet$ Trabalhadores \\
$\bullet$ Trabalhadores & $\bullet$ Estudantes \\
$\bullet$ Moradores & $\bullet$ Trabalhadores & $\bullet$ Investidores & $\bullet$ Trabalhadores & $\bullet$ Investidores & $\bullet$ Investidores \\
& & $\bullet$ Visitantes & & \\
& $\bullet$ Investidores & & & & \\
\hline
\end{tabular}

Fonte: pesquisa de campo.

Kotler et al.(1993) reforçam que uma cidade deve ter e conseguir oferecer infraestrutura básica: bons meios de transporte, energia barata, escolas com educação de qualidade, segurança, normas urbanísticas, espaços recreativos, bons hotéis e restaurantes. Todos os quesitos são ressaltados pelos públicos abrangidos pela pesquisa. 
Solicitados a descrever o que consideram como uma cidade para bem viver, apenas 21 dos 95 respondentes descreveram sua opinião, sistematizadas no quadro 4.

\section{Quadro 4- Quesitos de uma cidade para Bem Viver}

\section{O que possui uma Cidade para se Bem Viver}

* Uma cidade que tenha investimentos.

* Uma cidade que ofereça cultura, entretenimento além de segurança pública de qualidade.

* Uma cidade que tenha oferta de empregos bem remunerados, para que não se precise trabalhar em outro município.

* Uma cidade com oportunidades de trabalho, baixo custo de vida (aluguel, moradia, alimentação) e com qualidade de vida (áreas verdes para passeios, hospitais e segurança).

* Uma cidade com melhor aproveitamento dos recursos existentes.

* Uma cidade com mais opções de lazer.

* Uma cidade com trânsito rápido e incentivo ao turismo.

* Uma cidade com ruas asfaltadas, melhor mobilidade urbana.

* Uma cidade com mais lojas, bares, restaurantes, mercados, abertos em horários noturnos e finais de semana.

* Uma cidade com trânsito seguro, coleta seletiva de lixo.

* Uma cidade que possui um planejamento (plano diretor).

* Uma cidade que permita o uso de espaços públicos (praças, parques, avenidas...) e dá ênfase a convivência das pessoas; disponibiliza áreas de descanso, lazer, natureza; incentiva agenda de eventos culturais; serviços públicos confiáveis em termos de saúde, segurança, mobilidade e infraestrutura inclusiva.

* Uma cidade com hospitais de qualidade, comércio aberto nos finais de semana e bares com ótima recepção e alimentação de qualidade.

* Uma cidade com universidades comprometidas com a cultura e empresas que invistam na qualidade do atendimento e respeito aos clientes internos e externos.

* Uma cidade que seja limpa, arborizada e organizada.

* Uma cidade com qualidade em energia, água e esgoto além de segurança.

* Uma cidade com internet acessível a todos.

\section{Fonte: pesquisa de campo.}

Nas respostas é possível perceber a repetição de atributos já elencados como prioritários e poucos novos surgem espontaneamente. $\mathrm{O}$ resultado pode subsidiar o planejamento de uma cidade que seja considerada pelos cidadãos atrativa e prazerosa de se morar, estudar, trabalhar, investir e visitar.

\section{CONCLUSÃO}

As cidades são os laboratórios nos quais se descobrem, experimentam e aprendem certos requisitos indispensáveis para a solução dos problemas globais. A cidade é um organismo vivo, criado e gerido pelo homem e, como tal, está sujeita a falha, por isso, é preciso cuidá-la e fazê-la funcionar bem (LEITE, 2012). Bauman (2009) elege a cidade como a célula das transformações almejadas pela sociedade. Para o autor, nos lugares, quer denominemos de cidade, espaço, território, é que "se forma a experiência humana, que ela se acumula, é compartilhada, e que seu sentido é elaborado, assimilado e negociado" (p. 35).

Além do mais, "é nos lugares, e graças aos lugares, que os desejos se desenvolvem, ganham forma, alimentados pela esperança de realizar-se e correm o risco da decepção - e, a bem da verdade acabam decepcionados, na maioria das vezes"(p. 35).

Orientandos pelo preceito de Bauman (2009) a busca de entender os desejos dos atores envolvidos com a configuração de uma cidade/lugar movem essa pesquisa. Para minimizar, senão cortar a decepção mencionada pelo autor é mister o envolvimento de todos os setores na consecução dos objetivos de Bem Viver de um local. 
Leite (2012, p. 14) em sua abordagem sobre cidades inteligentes, destaca que as cidades se reinventam, "elas não são fossilizadas: as melhores cidades são aquelas que continuamente sabe se renovar, funcionam similarmente a um organismo - quando adoecem, se curam mudam". É preciso repensar as cidades, deixa-las mais sustentáveis, ou seja, transformá-las numa rede estratégica de núcleos policêntricos compactos e densos, otimizando infraestrutura e liberando territórios verdes.

Na concepção do autor, a sociedade contemporânea urge por novos modelos de cidade, mais justos e sustentáveis: o desafio é oportuno, desde que surja da atuação conjunta da sociedade civil organizada, do setor corporativo e, obviamente, da atuação pública eficiente, o maior gargalo em países como o Brasil.

Santos (2003, p. 96) geógrafo de renome merece ser lembrado quando afirma que "o território não é apenas o resultado de superposição de um conjunto de sistemas de coisas criadas pelo homem. O território é o chão e mais a população, isto é, uma identidade, o fato e o sentimento de pertencer àquilo que nos pertence".

A pesquisa seminal no projeto de estudo que orienta as autoras indica um campo fértil no âmbito ainda incipiente do marketing de cidades.

A materialidade das cidades, presente nas invocações dos atributos originados na pesquisa, como infraestrutura, estradas de acesso dentre outros, é, na abordagem de Pesavento (2007) a representação das imagens e discurso que definem uma cidade. Segue a autora, enfatizando que "a cidade é um fenômeno que se revela pela percepção de emoções e sentimentos dados pelo viver urbano e também pela expressão de utopias, de esperanças, de desejos e medos individuais e coletivos, que esse habitar em proximidades propicia" (p. 3).

\section{REFERENCIAS}

ANTUNES, J.E. As Cidades também Precisam de Marketing. Marketeer, p. 86-87, Mai. 2002.

BAUMAN, Z. Confiança e medo na cidade. Rio de Janeiro: Zahar, 2009.

COBRA, M. Administração de marketing no Brasil. 3 ed. Rio de Janeiro: Elsevier, 2009.

ETZKOWITZ, H. The triple helix: University-Industry-Government innovation in action. New York and London: Routledge, 2008.

HONORÉ, C. Devagar. Rio de Janeiro: Record, 2011.

KANTER, R. M. Classe mundial. Rio de Janeiro: Campus, 1966.

KEARS, G.; PHILO, C. Selling Places - the city as cultural capital past and present. Pergamon Press: Oxford, 1993.

KOTLER, P.; ARMSTRONG, G. Princípios de Marketing. 7 ed. Rio de Janeiro: LTC, 1999.

KOLTER, P.; GERTNER, D.; REIN, I.; HAIDER, D. Marketing de lugares: como conquistar crescimento de longo prazo na América Latina e no Caribe. São Paulo: Prentice Hall, 2006.

KOTLER, P.; KARTAJAYA, H.; SETIAWAN, I. Marketing 3.0: as forças que estão definindo o novo marketing centrado no ser humano. Rio de Janeiro: Elsevier, 2010.

LEITE, C. Cidades sustentáveis, cidades inteligentes: desenvolvimento sustentável num planeta urbano. Porto Alegre: Bookman, 2012.

MALHOTRA, N. K. Pesquisa de marketing: uma orientação aplicada. Porto Alegre: Bookman, 2001.

PESAVENTO, S. J. Cidades visíveis, cidades sensíveis, cidades imaginárias. Revista Brasileira de História, v. 27. n. 53. São Paulo: Jan/Junh. 2007.

PORTER, M. E. A vantagem competitiva das cidades. Revista Exame, Novembro, 1995. 
SANTOS, M. Por uma outra globalização: do pensamento único à consciência universal. Rio de Janeiro: Record, 2003.

WALKER, J. L. Service encounter satisfaction: conceptualized. Journal of services marketing, v. 9. 1995, p. 5-14

VAN DEN BERG, L.; BRAUN, E. Urban Competitiveness. Marketing and the need for organising capacity. Urban Studies, v.36, n.5-6, p. 987-999, 1999.

VIVACQUA, F. Cidades em transição. 2012, https://metodologiasinergicas.wordpress.com/2012/06/17/cidades-emtransicao-transition-towns/. Acesso em: 15/03/2015. 